\title{
Factors associated with trajectories of women's quality of life and association with substance use 12 months post-treatment
}

\author{
Hyunyong Park', Elizabeth M Tracy ${ }^{1 *}$, Meeyoung O Min¹, Lenore Kola ${ }^{1}$, Alexandre Laudet ${ }^{2}$ \\ From 2014 Addiction Health Services Research (AHSR) Conference \\ Boston, MA, USA. 15-17 October 2014
}

\section{Background}

Quality of life (QOL) has become an increasingly recognized component of recovery for women with substance use disorders (SUDs) [1-3]. However, little is known about different trajectories of QOL among women with SUD over time. This study: a) identified heterogeneous QOL trajectories; b) examined predictors related to QOL trajectories; and c) investigated the association between QOL trajectories and substance use 12 months post-treatment intake.

\section{Methods}

Data were collected from 377 women at three countyfunded treatment programs. Women were interviewed at 1 week, and at 1,6 , and 12 months post-treatment intake (81\% retention). The World Health Organization Quality of Life Measure (abbreviated version) assessed QOL over time. Latent Class Growth Model (LCGM) was performed to identify QOL trajectories of underlying subgroups of the women. The model fit was evaluated by the Bayesian Information Criteria and the sample sizes of the smallest class. Multinomial logistic regression explored demographic, clinical, and personal network factors associated with the QOL trajectories. Lastly, we explored the relationship between the QOL trajectories and substance use over 12 months.

\section{Results}

The majority of participants were African American $(60 \%)$, received government assistance $(72.5 \%)$, and had co-occurring mental and substance use disorders

\footnotetext{
* Correspondence: elizabeth.tracy@case.edu

'Jack, Joseph and Morton Mandel School of Applied Social Sciences,

Cleveland, OH, 44106, USA

Full list of author information is available at the end of the article
}

(73.4\%); 42 percent used alcohol and/or drugs during the 12 month follow-up period. Mean QOL at intake was $61.2(\mathrm{SD}=15.62)$.

LCGM indicated three different trajectories in QOL (Figure 1): a) consistently high QOL $(\mathrm{n}=108 ; 28.6 \%)$; $\mathrm{b})$ consistently moderate QOL $(\mathrm{n}=212 ; 56.2 \%)$; and $\mathrm{c})$ consistently decreasing QOL $(\mathrm{n}=57$; $15.1 \%)$. Multinomial logistic regression results (Table 1 ) shows that higher levels of trauma symptoms were associated with increased odds of belonging to the decreasing QOL group compared to either high QOL group or the moderate QOL group. Higher levels of abstinence self-efficacy and greater number of close network members were associated with decreased odds of belonging to the decreasing QOL group. Compared to the moderate QOL group, a greater number of critical network members were associated with increased odds of belonging to the decreasing QOL group. The decreasing QOL group was more likely to use substances at 12 months post-treatment intake $(\mathrm{OR}=3.48 ; 95 \% \mathrm{CI}=1.62,7.50)$ compared to the high QOL group.

\section{Conclusions and implications}

Findings highlight three distinctive QOL trajectories and their association with substance use treatment outcome. Fifteen percent of the women had consistently low levels of QOL, which decreased over time and increased odds of substance use post-treatment, suggesting this group may need targeted intervention and follow-up.

\footnotetext{
Acknowledgements

Research funded by a grand from the National Institute on Drug Abuse (NIDA) R01 DA022994. The authors have no financial relationships related to the topic of this presentation. The content is solely the responsibility of the authors and does not necessarily represent the official views of NIDA or the $\mathrm{NIH}$.
} 


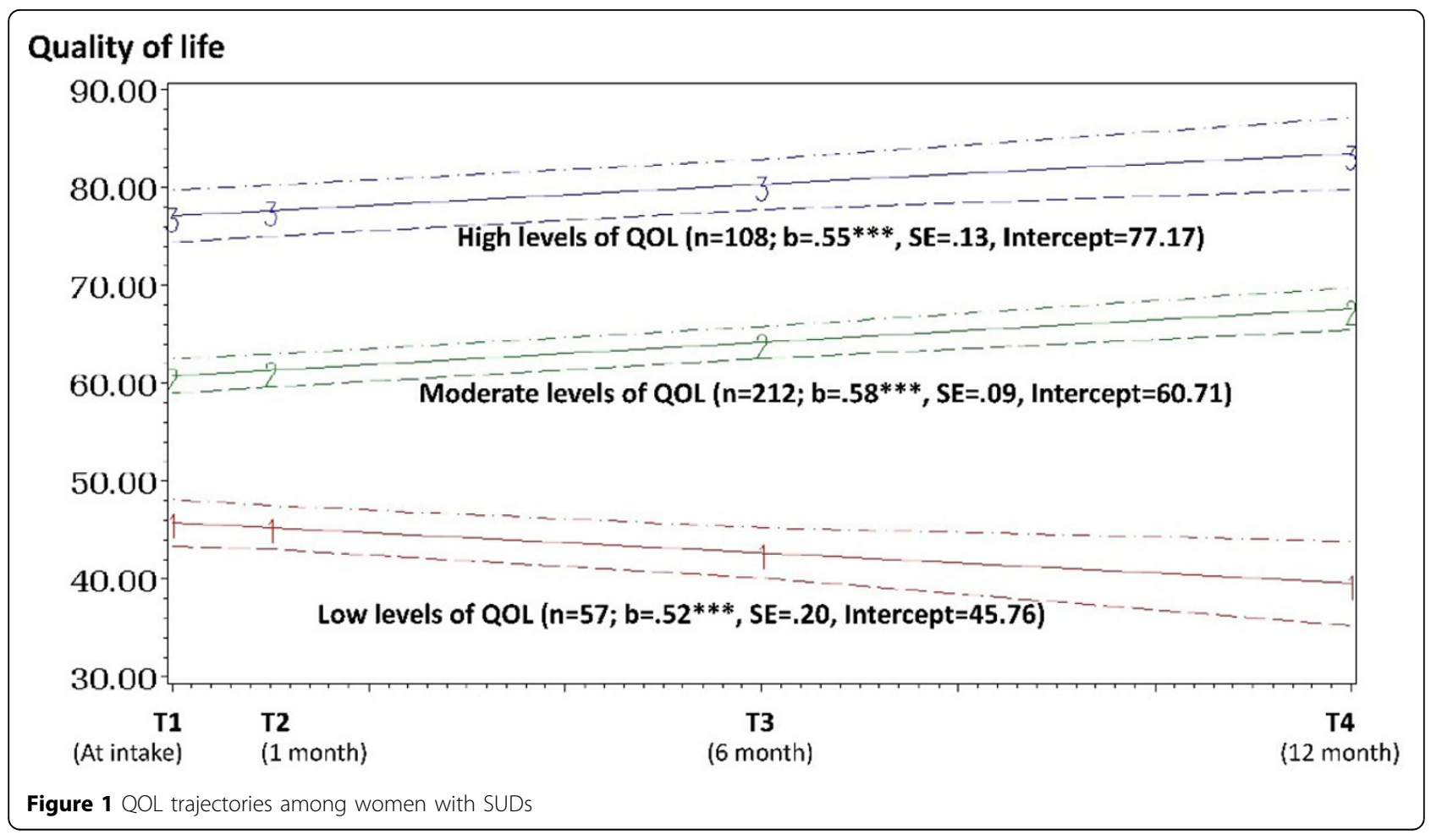

Table 1 Results of multinomial logistic regression

\begin{tabular}{|c|c|c|c|}
\hline & Decreasing QOL vs. High QOL (ref) & Moderate QOL vs. High QOL (ref) & Decreasing QOL vs. Moderate QOL (ref) \\
\hline & $O R(95 \% C l)$ & $O R(95 \% C l)$ & $O R(95 \% C l)$ \\
\hline Treatment Modality & $1.73(0.65,4.59)$ & $0.78(0.41,1.49)$ & $2.22(0.98,5.04)$ \\
\hline Unstable Housing & $2.41(0.84,6.85)$ & $1.27(0.57,2.82)$ & $1.90(0.85,4.25)$ \\
\hline Dual Disorder & $0.99(0.34,2.92)$ & $1.07(0.58,1.99)$ & $0.93(0.35,2.45)$ \\
\hline Trauma Symptoms & $1.08(1.06,1.11)$ & $1.03(1.02,1.05)$ & $1.05(1.03,1.07)$ \\
\hline Abstinence Self-Efficacy & $0.97(0.95,0.99)$ & $0.98(0.96,0.99)$ & $0.99(0.98,1.01)$ \\
\hline Substance using Alters & $1.01(0.92,1.11)$ & $1.05(0.99,1.12)$ & $0.97(0.89,1.04)$ \\
\hline Concrete Support & $0.95(0.88,1.03)$ & $1.00(0.95,1.05)$ & $0.95(0.89,1.02)$ \\
\hline Sobriety Support & $0.98(0.89,1.08)$ & $1.03(0.97,1.11)$ & $0.95(0.88,1.03)$ \\
\hline Reciprocal Relationship & $0.93(0.84,1.03)$ & $0.97(0.92,1.04)$ & $0.96(0.88,1.04)$ \\
\hline Very Close Alters & $0.86(0.78,0.94)$ & $0.93(0.88,0.98)$ & $0.92(0.85,1.002)$ \\
\hline Critical Alters & $1.04(0.95,1.13)$ & $0.95(0.89,1.01)$ & $1.09(1.004,1.18)$ \\
\hline
\end{tabular}

Note. Boldface indicates statistical significance at alpha level of .05 .

\section{Authors' details}

'Jack, Joseph and Morton Mandel School of Applied Social Sciences, Cleveland, $\mathrm{OH}, 44106, \mathrm{USA} .{ }^{2}$ National Development and Research Institutes, Inc., New York, NY, 10010,

Published: 20 February 2015

\section{References}

1. Center for Substance Abuse Treatment.: National Summit on Recovery: Conference Report 2007, DHHS Publication No. (SMA) 07-4276. Substance Abuse and Mental Health Services Administration, Rockville, MD.

2. Laudet: What does recovery mean to you? Lessons from the recovery experience for research and practice. J Subst Abuse Treat 2007, 33:243-256.
3. Tracy EM, Laudet A, Min MO, Kim H, Brown S, Jun M, Singer L: Prospective patterns and predictors of quality of life among women in substance abuse treatment. Drug Alcohol Depend 2012, 124:242-249.

doi:10.1186/1940-0640-10-S1-A47

Cite this article as: Park et al:: Factors associated with trajectories of women's quality of life and association with substance use 12 months post-treatment. Addiction Science \& Clinical Practice 2015 10(Suppl 1):A47. 